\title{
Drug Accountability Record Subcategorization
}

National Cancer Institute

\section{Source}

National Cancer Institute. Drug Accountability Record Subcategorization. NCI Thesaurus.

Code C83141.

A sub-division of the drug accountability classification. 